\title{
Entrepreneurship and Economic Freedom: Do Objective and Subjective Data Reflect the Same Tendencies?
}

\author{
Burak Erkut
}

\begin{abstract}
A B S T R A C T
Objective: The paper addresses the question whether the same tendencies on entrepreneurship, innovation and economic freedom can be captured by subjective (Global Entrepreneurship Monitor) and objective (Index of Economic Freedom) data - and to which extent one can classify countries by different data sources in a theoretical framework based on the national competitiveness of each country.
\end{abstract}

Research Design \& Methods: Main method used was the direct discriminant analysis. Since this approach has shortcomings, selected variables from an exhaustive CHAID analysis (Erkut, 2016a) were used to predict the degree of economic freedom of the country based on the answers of experts.

Findings: To determine the degree of economic freedom in a country, the effective enforcement of intellectual property rights legislation and quick access to utilities are the two variables with the most informational content. $86.8 \%$ of the original grouped cases was classified correctly - this is above the widely accepted threshold of $75 \%$.

Implications \& Recommendations: A new trend in entrepreneurial research is to build compound indices based on different data sources. It is important to understand whether parts of a compound index reflect the same tendencies. This paper gives formal empirical evidence supporting this hypothesis.

Contribution \& Value Added: The contribution of this work lies in closing a research gap defined by Coduras and Autio (2013) concerning Global Entrepreneurship Monitor, suggesting that GEM results should be tested against objective data sources such as Index of Economic Freedom.

\begin{tabular}{ll}
\hline Article type: & research paper \\
& entrepreneurship; economic freedom; innovation; discriminant \\
Keywords: & analysis
\end{tabular}

JEL codes: $\quad$ C53, L26, O38

Received: 19 January 2016 Revised: 8 June 2016 Accepted: 28 July 2016

\section{Suggested citation:}

Erkut, B. (2016). Entrepreneurship and Economic Freedom: Do Objective and Subjective Data Reflect the Same Tendencies? Entrepreneurial Business and Economics Review, 4(3), 11-26, DOI: http://dx.doi.org/10.15678/EBER.2016.040302 


\section{INTRODUCTION}

Although the concept of economic freedom is a subjective matter, surveys and composite indices were constructed in the past to measure the degree of economic freedom, as well as entrepreneurship activity and how innovative individual countries are.

Research on entrepreneurial activity has increased in the recent years. According to Coduras and Autio (2013, p. 49), more effort has to be put to determine the usefulness of the data resources on entrepreneurship, since the tendency is to offer integrated information instead of observing partial aspects in an isolated fashion - in other words, integrated indices on entrepreneurship need a careful selection of indicators. According to Coduras and Autio (2013), the most advanced integrated index is the Global Entrepreneurship and Development Index (GEDI), proposed by Zoltan Acs and Laszlo Szerb in 2008. This integrated index uses objective and subjective data to bridge the gap between entrepreneurship, individuals and institutions.

The focus of this paper is on the Global Entrepreneurship Monitor (GEM) and the Index of Economic Freedom (IEF). GEM is a subjective survey bridging the gap between innovativeness and entrepreneurship, thus differing from other indexes and focusing both on the opinions of experts as well as citizens, trying to categorize the participating countries by means of their economic activities and innovative openness. IEF is an index based on hard facts of the participating countries, which tries to categorize countries by their degree of economic freedom - emphasizing how easy or hard it is for the individuals to "work, produce, consume and invest" (Heritage Foundation, 2016) without any significant impediments. Both data sources are used in the GEDI.

The research question is whether the same tendencies on entrepreneurship, innovation and economic freedom can be captured by subjective (GEM) and objective (IEF) data - and to which extent one can classify countries by different data sources in a theoretical framework based on national competitiveness of each country.

This research question will be answered by using linear discriminant analysis based on previously selected variables by a decision tree algorithm (Erkut, 2016a) as an attempt to reduce the dimension of the data. The selected variables will be used to understand whether one can have the same classification for the degree of economic freedom with the subjective data on entrepreneurship. The rest of the paper is as follows: After a literature review, the theoretical models of GEM and IEF will be introduced. The methods will be clarified; the results will be presented and discussed. A conclusion follows, where the limitations on research will be discussed.

\section{LITERATURE REVIEW}

Since the research trend is tending to build composite entrepreneurship indicators based on subjective and objective data, the importance of data sources to be used in such indicators must be analysed deeply, and it is necessary to put more effort for the assessment of the relevance of information sources to the entrepreneurial research context. Entrepreneurial measurements should offer integrated information to the users (Coduras \& Autio, 2013, pp. 48-49). These measurements necessarily need to combine both the perceptions regarding entrepreneurship and hard facts from objective data. 
The context of the research is framed within the background of market processes, where entrepreneurs are the driving forces behind these processes. To be more precise, entrepreneurs are seen as forces that are "keeping the economy in continual motion, urged on to incessant progress" (Gustafson, 1992, p. 5). For the emergence of long-term growth, both technological progress and the associated introduction of novelties (innovative services and goods) to the economy are the most important causal factors (Lehmann-Waffenschmidt, 2008, p. 108).

Indeed, to avoid the pretence of knowledge (Hayek, 1989), not central planners but individuals can be entrepreneurially active and offer solutions to problems they perceive in the society, with their uniquely possessed knowledge, since "the knowledge of circumstances of which we must make use never exists in concentrated or integrated form, but solely as the dispersed bits of incomplete and frequently contradictory knowledge which all the separate individuals possess." (Hayek, 1945, p. 519). Entrepreneurial discovery drives market processes (Kirzner, 1997, p. 62). According to Wong, Ho and Autio (2005, p. 345), high potential total early stage entrepreneurial activity is the only factor which has a significant effect on growth rates. This hypothesis was confirmed in a crosscountry, Cobb-Douglas production function type context in the authors' research.

Individuals' entrepreneurial activity alone is necessary, but not sufficient for the long-term sustainable economic performance of a country - the idea behind fiscal freedom goes back to low tax burdens for entrepreneurial activity. Ockey (2011) uses the data from IEF to test the hypothesis of a positive correlation between economic freedom and fiscal performance. The results of this paper confirm this hypothesis; furthermore, the results also suggest that trade freedom and property rights also contribute to the economic performance of a country, the latter having a positive relationship with fiscal performance (Ockey, 2011, p. 15).

Employing the idea of disaggregating the determinants of economic freedom, Heckelman and Stroup (2000) focus on the isolated effects of the non-aggregated determinants of economic freedom on economic growth, by using a procedure based on the relevance of each factor determined by a multivariate regression procedure. According to their findings, "differences in economic freedoms between nations can explain almost half of the variation in growth" (Heckelman \& Stroup, 2000, p. 542). The conclusion is in line with Erkut's (2016a) empirical work regarding the structural similarities of countries for competitiveness and innovation.

In this study, Erkut (2016a) focuses on the GEM national experts survey (NES) dataset for understanding how similar experts from countries belonging to the same stage of economic development observe impediments on competitiveness and innovativeness of their country. By using a decision tree algorithm, the author extracts 12 variables that describe more than half of the variation within the dataset. Effectiveness of governmental institutions, intellectual property legislation, gender equality, quick access to utilities and the discovery of opportunities by young entrepreneurs to establish new firms altogether constitute the most important factors extracted to explain the variation in the dataset.

Especially the role of intellectual property rights as the variable with the highest explanatory power (Erkut, 2016a) suggest the move towards a knowledge-based economy, where freedoms of individuals engaging in economic activities play an important role "to 
pursue, explore or implement new ideas" (Audretsch \& Thurik, 2000, p. 24). Therefore, policy designs should aim to deliver strategies for the emergence of firms' success and their sustainability (Audretsch \& Thurik, 2000, p. 32) without intervening in the planning decisions of individuals. In this sense, understanding economic freedom and impediments towards reaching economic freedom gain importance.

Snodgrass (2008) compares alternative business enabling environment indices based on those countries, in which USAID works. He finds out that GEM findings on bureaucracy differs from the Doing Business Index of the World Bank by means of the ranking of countries, and based on this fact, he says that "no one index merits exclusive reliance" (Snodgrass, 2008, p. 12).

Hanke and Walters (1997, p. 126) find out that IEF is positively correlated with the Economic Freedom of the World Index of the Fraser Institute. According to the authors, differences between the two indices are in their views of monetary policy and government size, the latter being neutral in case of government size. This is a critical point in answering the question of who will plan the economic activity in a country. Hayek (1945, p. 524) asks this question for clarifying responses to "rapid adaptation to changes in particular circumstances of time and place", where a central board cannot be efficient on deciding what to plan for the economy. The policy implication is known to be the decentralisation of the economy, where government intervention does not occur; through that way, individuals can plan accordingly, using their specific knowledge to provide solutions to market gaps. In line with Hayek's (1945) point of view, IEF is chosen to be the index capturing this necessary aspect of knowledge problem in the society.

In an early work, McMullen, Bagby and Palich (2008) focus on opportunity-motivated entrepreneurship and necessity-motivated entrepreneurship and explain them with the ten factors of economic freedom as well as GDP level. The novelty of their paper lies within the two distinctions of entrepreneurial activity and how these two are differently influenced by government's different restrictions on different factors of economic freedom (McMullen et al., 2008, p. 889).

In an attempt to compare GEM and IEF, Diaz-Casero, Diaz-Aunion, SanchezEscobedo, Coduras and Hernandez-Mogollon (2012, p. 1708) make use of three questions building together the total entrepreneurial activity index. According to the findings, government size and fiscal freedom fosters entrepreneurial activity. Furthermore, for the group of countries classified as innovation-driven economies, an overall increase in economic freedom has a positive impact on opportunity based entrepreneurship.

Kuckertz, Berger and Mqepa (2016) employ a fuzzy-set qualitative comparative analysis approach for analysing the link between economic freedom and entrepreneurial activity based on IEF. The focus on configurations of the factors of economic freedom shows that these vary according to the stage of economic development (Kuckertz et al., 2016 , p. 1292). The authors conclude that economic freedom is more able to explain necessity driven entrepreneurship than opportunity driven entrepreneurship.

Although there is this distinction in the literature, it is true that both necessity driven and opportunity driven types of entrepreneurship go back to the introduction of a novel product to the economy, where perceptions of economic actors play an important role in perceiving information and transferring it to knowledge in their minds. Since knowledge is dispersed in the society, every economic actor possesses a piece of the dispersed 
knowledge, which is their competitive advantage if they utilize this knowledge in form of a product and the corresponding business conception (Erkut, 2016b). Therefore, the role of perceptions in new product development becomes equivalently important for both the opportunity driven and the necessity driven types of entrepreneurship. This is what Erkut (2016b) calls the nano-dimension of the evolutionary economic analysis, which becomes the necessary step prior to the generation of knowledge.

Coduras and Autio (2013) implement an empirical methodology using discriminant and regression analyses; their focus is on the comparison of the Global Entrepreneurship Monitor with the Global Competitiveness Index $(\mathrm{GCl})$. The authors find out that the GEM data can be seen as a complementary data source to the $\mathrm{GCl}$ (Coduras \& Autio, 2013, p. 71). For further research, they suggest a research program based on the comparison of GEM with other relevant, subjective (IEF) and objective (Ease of Doing Business Index) data sources which are used to build up the composite GEDI, which is the point of departure for the research question to be answered in this analysis.

In this sense, this analysis can be seen as a continuation of the Coduras-Autio research program on comparison of different data sources composing GEDI for the tendency of concordance. This analysis is needed for understanding the importance of complementary objective and subjective data sources. It can also be the source of ideas towards shaping the economic landscape for enabling entrepreneurial activity in a free market economy without impediments or bureaucracy that keep individuals away from shaping the market process.

\section{MATERIAL AND METHODS}

\section{Theoretical GEM Model}

GEM was launched with the target of creating a possibility for the comparison of entrepreneurship on an international level in 1997 (Kelley, Bosma \& Amoros, 2011, p. 61). Bosma, Coduras, Litovsky and Seaman (2012, p. 4) state that until the launch of GEM, an international comparison of entrepreneurial data was not possible due to differences in government databases and missing entrepreneurial data in some countries.

GEM defines entrepreneurship as "any attempt at new business or new venture creation, such as self-employment, a new business organization, or the expansion of an existing business, by an individual, a team of individuals, or an established business" (Bosma et al., 2012, p. 20).

GEM's objectives are based on a number of premises, which implicitly imply the economic freedom of individuals in a broad sense (Bosma et al., 2012, pp. 7-8): (1) Economic growth depends on the dynamics of the entrepreneurial activities, (2) Economies requires individuals who are able and motivated to be entrepreneurs, and a society accepting and supporting entrepreneurs, (3) Entrepreneurs need to be ambitious.

Since the first GEM global study in 1999, both quality of the research methodology and the quality of surveys tend to increase. GEM comprises a wide range of developing and developed economies of over 50 nations and is conducted by a consortium of universities. It differs from other surveys on the same field by means of two guiding purposes (Kelly et al., 2011, pp. 13-15): First of all, GEM aims to focus on venture creation, whereas other studies on entrepreneurship focus on firm-level data. Second, GEM aims 
to promote entrepreneurship as an ongoing, dynamic process. Implicitly, this second guiding purpose implicitly describes entrepreneurship as a living organism with the phases beginning "from intending to start, to just starting, to running new or established enterprises and even discontinuing these" entrepreneurial activities (Kelley et al., 2011, p. 13). It categorizes countries by means of their entrepreneurial activities according to the theoretical framework of national competitiveness by Porter (1990a, 1990b).

GEM is based on two parts: an adult population survey (APS) and a national experts survey, which both are subdivided into global-individual level datasets and national summaries. APS is aimed to identify aspirations, entrepreneurial attitudes and activities of individuals, whereas NES is targeted at (at least 36) national experts of each country, which focuses on the nine key Entrepreneurial Framework Conditions (EFC) which are listed as finance, government policies, government programs, entrepreneurial education and training, R\&D transfer, commercial and professional infrastructure, internal market openness, physical infrastructure and services, cultural and social norms (see e.g. the website of GEM consortium) and further topics listed as degree of skills and abilities to start up in the population, opportunities to start up, high growth businesses support, women's entrepreneurship support, and encouragement in addition. These EFC are associated with the theoretical model of Porter (Ahlstrom \& Bruton, 2010, p. 437).

The current, revised GEM model relies on the typology of Porter (1990a, 1990b) to categorize the economies as "factor-driven", "efficiency-driven" and "innovation-driven" within an entrepreneurial framework. The target of the revision was set to be the description and the measurement of the conditions, which can lead to economic growth based on entrepreneurship and innovation.

\section{Theoretical IEF Model}

IEF was launched jointly by The Wall Street Journal and The Heritage Foundation (an American conservative think tank) in 1995 with the aim of developing "a systematic, empirical measurement of economic freedom in countries throughout the world" (Holmes, Feulner \& O'Grady, 2008, p. 1).

IEF defines economic freedom as a notion which encompasses "all liberties and rights of production, distribution, or consumption of goods and services" (Miller \& Kim, 2010, p. 58). With the existence of the rule of law and the protection and respect of the individual freedoms by the state, people should be able to consume, produce, invest and work freely. Based on this definition, economic freedom is measured by using ten different components, which are relevant to economic development and national welfare as well as the welfare of each individual. The ten economic freedoms are (1) business freedom ("the individual's freedom for founding and running a firm without state intervention"), (2) trade freedom ("how open is the economy to international trade"), (3) fiscal freedom ("to what extent does the government permit persons to use their income and wealth for themselves"), (4) government spending ("is there excessive government spending which may lead to a crowding out of the private consumption?"), (5) monetary freedom ("is the currency stable?", "are the prices determined by markets?"), (6) investment freedom ("is there an open investment environment?"), (7) financial freedom ("how transparent is the financial system?"), (8) property rights ("are people able to accumulate private property and wealth?"), (9) freedom from corruption ("do the individuals gain personally at the expense of the whole by being dishonest?") and (10) labour 
freedom ("are the individuals able to work as much as they want and wherever they want?"). Each component is scored on a 0 to 100 scale individually. The simple average of these scores builds the overall economic freedom of a nation (Miller \& Kim, 2010, p. 60), where each component is treated equally. For each component, there are different data sources to calculate the score (for the calculation methods see the Miller \& Holmes, 2010, pp. 457-468).

\section{Discriminant Analysis}

The purpose of the analysis is to compare the results of GEM expert survey with the IEF results as different sources of information regarding entrepreneurship and to understand if one can classify countries for the degree of economic freedom according to IEF with the results of GEM expert survey.

Therefore, the research hypothesis is that the GEM NES results can classify the 53 nations participating in GEM for the corresponding IEF stages of economic freedom. Since GEM NES results are subjective results based on the opinions of experts, whereas IEF results are objective results based on statistics and economic hard facts, the aim is to analyse if one can find a link between objective and subjective data on entrepreneurship and economic freedom.

Discriminant analysis consists of two sources of data: The results of the 2010 GEM NES survey and the economic freedom scores of 2010 IEF. A methodological issue arises from the categorization of countries according to their respective economic freedom scores. In the 2010 IEF, there are 4 countries categorized as "repressed", 11 countries which are categorized as "mostly unfree", 27 countries which are categorized as "moderately free", 9 countries which are categorized as "mostly free" and only 2 countries which are categorized as "free". Of course, this classification does not reflect the whole IEF but only the proportion of 53 countries which are considered in both GEM and IEF. Because of this uneven distribution, these five groups will be combined into three groups; "repressed/mostly unfree" with 15 countries, "moderately free" with 27 countries and "mostly free/free" with 11 countries. The aim of this reduction is to have enough observations for all categories to proceed with the analysis.

Independent variables are those that are selected by a decision tree algorithm to describe the data set in a reduced dimension, explaining $56 \%$ of the variance in the data set (Erkut, 2016a). These are Likert scaled variables, which can be treated as interval scales for data analysis (Brown, 2011). The method for the discriminant analysis is the direct method, which takes in all the independent variables simultaneously in the analysis. For three categories, two discriminant functions will be estimated. The starting point is a univariate ANOVA analysis, which shows how each independent variable can classify the three groups individually. For the classification, the a-priori probabilities will be chosen to be computed from the group sizes. Also, separate covariance matrices will be used. The strength of this method is drawing boundaries between groups of data with the target, having similar data points (in terms of their closeness) in the same group and having different data points in different groups. However, it is fair to mention that this method does not work if there is not a minimum number of cases in each group. 


\section{RESULTS AND DISCUSSION}

\section{Results}

From the univariate ANOVA analysis (Table 1), it can be seen that five out of twelve variables can classify the three groups significantly with a given 0.05 significance level.

Table 1. Univariate ANOVA Analysis

\begin{tabular}{|l|c|c|c|c|c|}
\hline \multicolumn{1}{|c|}{ Variables } & $\begin{array}{c}\text { Wilks' } \\
\text { Lambda }\end{array}$ & F & df1 & df2 & Sig. \\
\hline $\begin{array}{l}\text { Intellectual Property Rights (IPR) legislation } \\
\text { is efficiently enforced }\end{array}$ & 0.510 & 24.067 & 2 & 50 & 0.000 \\
\hline $\begin{array}{l}\text { New or growing firms can get good access to utilities } \\
\text { (gas, water, electricity, sewer) in about a month }\end{array}$ & 0.600 & 16.666 & 2 & 50 & 0.000 \\
\hline $\begin{array}{l}\text { Sufficient debt funding available for new } \\
\text { and growing firms }\end{array}$ & 0.986 & .348 & 2 & 50 & 0.708 \\
\hline $\begin{array}{l}\text { Good opportunities for new firms have considerably } \\
\text { increased in the past five years }\end{array}$ & 0.986 & .361 & 2 & 50 & 0.699 \\
\hline $\begin{array}{l}\text { Colleges and universities provide good and adequate } \\
\text { preparation for starting up and growing new firms }\end{array}$ & 0.930 & 1.875 & 2 & 50 & 0.164 \\
\hline $\begin{array}{l}\text { Men and women get equally exposed to good } \\
\text { opportunities to start a new business }\end{array}$ & 0.959 & 1.064 & 2 & 50 & .353 \\
\hline $\begin{array}{l}\text { Plenty of good opportunities for the creation } \\
\text { of new firms }\end{array}$ & 0.958 & 1.105 & 2 & 50 & 0.339 \\
\hline $\begin{array}{l}\text { More good opportunities for the creation of new firms } \\
\text { than there are people able to take advantage of them }\end{array}$ & 0.980 & 0.499 & 2 & 50 & 0.610 \\
\hline $\begin{array}{l}\text { Government programs aimed at supporting new } \\
\text { and growing firms are effective }\end{array}$ & 0.829 & 5.139 & 2 & 50 & 0.009 \\
\hline $\begin{array}{l}\text { A wide range of government assistance for new } \\
\text { and growing firms can be obtained through contact } \\
\text { with a single agency }\end{array}$ & 0.865 & 3.895 & 2 & 50 & 0.027 \\
\hline $\begin{array}{l}\text { Science parks and business incubators provide } \\
\text { effective support for new and growing firms }\end{array}$ & 0.713 & 10.048 & 2 & 50 & 0.000 \\
\hline $\begin{array}{l}\text { Most people consider becoming an entrepreneur } \\
\text { as a desirable career choice }\end{array}$ & 0.944 & 1.471 & 2 & 50 & 0.240 \\
\hline
\end{tabular}

Source: Author's own calculations using SPSS.

In table 2 the functions at group centroids can be seen. It is important to see that function 1 separates the mostly free or free countries from those which are moderately free and repressed or mostly unfree; centroids are average discriminant scores for each discriminant function.

At this stage, the goodness of fit of the discriminant functions has to be understood. For this purpose, the eigenvalues and Wilks' Lambda for the two discriminant functions can be observed in tables 3 and 4 respectively.

From the eigenvalues, one can see that with $16.1 \%$ of the explained variance, the second discriminant function has a lower explanatory power than the first one, which explains $83.9 \%$ of the variance. Canonical correlations are 0.786 and 0.488 respectively.

The relative importance of each variable can be seen from the structure matrix in table 5 , where correlations of the variables with the discriminant functions are given. The 
given correlations are Pearson correlation coefficients and show that the variables "In my country, the Intellectual Property Rights (IPR) legislation is efficiently enforced", "In my country, new or growing firms can get good access to utilities (gas, water, electricity, sewer) in about a month", "In my country, science parks and business incubators provide effective support for new and growing firms", "In my country, Government programs aimed at supporting new and growing firms are effective", and "In my country, a wide range of government assistance for new and growing firms can be obtained through contact with a single agency" have a higher correlation with the first discriminant function.

Table 2. Functions at group centroids

\begin{tabular}{|l|c|c|}
\hline \multicolumn{1}{|c|}{ Country group at IEF Report 2010, 3 Categories } & $\mathbf{1}$ & $\mathbf{2}$ \\
\hline Repressed / Mostly Unfree & -1.444 & -0.586 \\
\hline Moderately Free & -0.063 & 0.532 \\
\hline Mostly Free / Free & 2.123 & -0.505 \\
\hline
\end{tabular}

Source: Author's own calculations using SPSS.

Table 3. Eigenvalues

\begin{tabular}{|c|c|c|c|c|}
\hline Function & Eigenvalue & \% of Variance & Cumulative \% & Canonical Correla- \\
\hline 1 & $1.619^{\mathrm{a}}$ & 83.9 & 83.9 & 0.786 \\
\hline 2 & $0.312^{\mathrm{a}}$ & 16.1 & 100.0 & 0.488 \\
\hline
\end{tabular}

a. First 2 canonical discriminant functions were used in the analysis.

Source: Author's own calculations using SPSS.

Table 4. Wilks' Lambda

\begin{tabular}{|c|c|c|c|c|}
\hline Test of Function(s) & Wilks' Lambda & Chi-square & df & Sig. \\
\hline 1 through 2 & 0.291 & 54.919 & 24 & 0.000 \\
\hline 2 & 0.762 & 12.077 & 11 & 0.358 \\
\hline
\end{tabular}

Source: Author's own calculations using SPSS.

The variables "In my country, most people consider becoming an entrepreneur as a desirable career choice", "In my country, Colleges and universities provide good and adequate preparation for starting up and growing new firms", "In my country, there are plenty of good opportunities for the creation of new firms", "In my country, there are more good opportunities for the creation of new firms than there are people able to take advantage of them", "In my country, there is sufficient debt funding available for new and growing firms" and "In my country, men and women get equally exposed to good opportunities to start a new business" have a higher correlation with the second discriminant function.

The classification results on table 6 give an idea on how well the group memberships were predicted. Here, it can be seen that $86.8 \%$ of the original grouped cases was classified correctly. Since a widely accepted threshold in the literature is $75 \%$ and above, the discriminant analysis is acceptable.

Figure 1 is the all-groups scatter plot, which is based on the centroids of the three categories and the two estimated discriminant functions. The vertical axis has the values of the second function, whereas the horizontal axis has the values of the first function. The group (class) memberships were plotted with different types of points. 


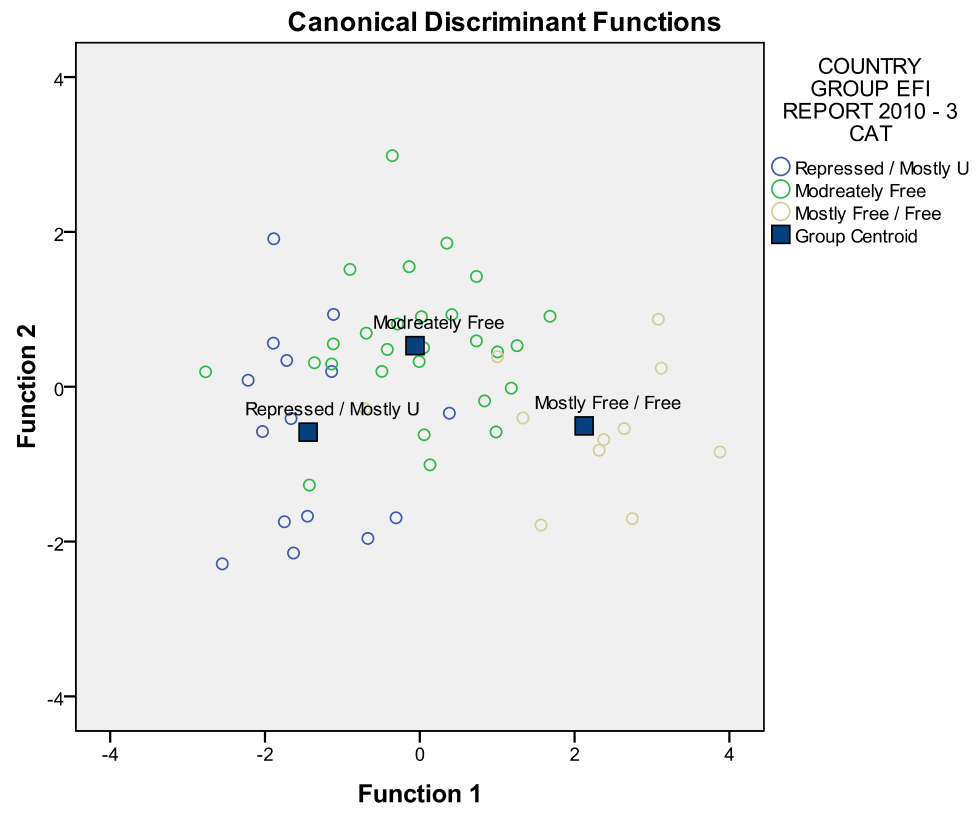

Figure 1. All-groups scatter plot

Source: Author's own illustration using SPSS.

Table 5. Structure Matrix

\begin{tabular}{|l|c|c|}
\hline \multicolumn{1}{|c|}{ Variables } & $\mathbf{1}$ & $\mathbf{2}$ \\
\hline Intellectual Property Rights (IPR) legislation is efficiently enforced & $0.768^{*}$ & -0.149 \\
\hline $\begin{array}{l}\text { New or growing firms can get good access to utilities (gas, water, electricity, } \\
\text { sewer) in about a month }\end{array}$ & $0.631^{*}$ & 0.262 \\
\hline $\begin{array}{l}\text { Science parks and business incubators provide effective support for new and } \\
\text { growing firms }\end{array}$ & $0.492^{*}$ & -0.174 \\
\hline $\begin{array}{l}\text { Government programs aimed at supporting new and growing firms are effec- } \\
\text { tive }\end{array}$ & $0.349^{*}$ & -0.168 \\
\hline $\begin{array}{l}\text { A wide range of government assistance for new and growing firms can be } \\
\text { obtained through contact with a single agency }\end{array}$ & $0.303^{*}$ & 0.155 \\
\hline $\begin{array}{l}\text { Good opportunities for new firms have considerably increased in the past five } \\
\text { years }\end{array}$ & $-0.093^{*}$ & 0.035 \\
\hline Most people consider becoming an entrepreneur as a desirable career choice & -0.104 & $0.364^{*}$ \\
\hline $\begin{array}{l}\text { Colleges and universities provide good and adequate preparation for starting } \\
\text { up and growing new firms }\end{array}$ & 0.154 & $0.343^{*}$ \\
\hline Plenty of good opportunities for the creation of new firms & 0.087 & $-0.320^{*}$ \\
\hline $\begin{array}{l}\text { More good opportunities for the creation of new firms than there are people } \\
\text { able to take advantage of them }\end{array}$ & -0.056 & $-0.219^{*}$ \\
\hline Sufficient debt funding available for new and growing firms & 0.019 & $0.207^{*}$ \\
\hline $\begin{array}{l}\text { Men and women get equally exposed to good opportunities to start a new } \\
\text { business }\end{array}$ & 0.144 & $-0.169^{*}$ \\
\hline
\end{tabular}

Pooled within-groups correlations between discriminating variables and standardized canonical discriminant functions. Variables ordered by absolute size of correlation within function.

* Largest absolute correlation between each variable and any discriminant function

Source: Author's own calculations using SPSS. 
Grey butterfly-like points representing mostly free and free countries are found at top right in the diagram, with high values of the first discriminant function and low values of the second discriminant function. Moderately free countries are found at the centre of the diagram with relatively higher values of the second discriminant function and relatively lower values of the first discriminant function; they are represented with rhombus black dots. Mostly unfree and repressed countries are found in the bottom left of the diagram with negative values of both discriminant functions; they are represented with round black dots.

Table 6. Classification Results

\begin{tabular}{|c|c|c|c|c|}
\hline \multirow{2}{*}{$\begin{array}{l}\text { Country group } \\
\text { at IEF Report } 2010\end{array}$} & \multicolumn{3}{|c|}{ Predicted Group Membership } & \multirow[b]{2}{*}{ Total } \\
\hline & $\begin{array}{l}\text { Repressed / } \\
\text { Mostly Unfree }\end{array}$ & $\begin{array}{l}\text { Moderately } \\
\text { Free }\end{array}$ & $\begin{array}{c}\text { Mostly Free / } \\
\text { Free }\end{array}$ & \\
\hline Repressed / Mostly Unfree & 12 & 3 & 0 & 15 \\
\hline Moderately Free & 2 & 25 & 0 & 27 \\
\hline Mostly Free / Free & 0 & 2 & 9 & 11 \\
\hline Repressed / Mostly Unfree & 80.0 & 20.0 & 0 & 100 \\
\hline Moderately Free & 7.4 & 92.6 & 0 & 100 \\
\hline Mostly Free / Free & 0 & 18.2 & 81.8 & 100 \\
\hline
\end{tabular}

Source: Author's own calculations using SPSS.

Although there are some outliers for the latter two cases, the conclusion is that a country with a high value of the first discriminant function and a low value of the second discriminant function can be assigned to the group of mostly free and free countries, whereas a country with low values of both functions can be assigned to the group of repressed and mostly unfree countries. A country with a high value of the second discriminant function and a low value of the first discriminant function can be assigned to the group of moderately free countries. Of course, due to the situation with the outliers, there might be difficulties with the classification, but it is not expected to classify $100 \%$ correctly due to different natures of objective and subjective data.

\section{Discussion}

Discriminant analysis is the main finding of this empirical research and gives answer to the question whether it is possible to classify the GEM NES participating nations in the corresponding stage of economic freedom according to IEF.

The result of the discriminant analysis was given as two discriminant functions. With the discriminant analysis, the correct classification of nations for the degree of economic freedom based on the subjective information given from GEM NES was $86.8 \%$, which is a high correct classification rate.

It can be said that the classification was especially successful for moderately free countries (92.6\% of the cases were classified correctly) and less successful for repressed/mostly unfree countries ( $80 \%$ of the cases were classified correctly) and mostly free/free countries ( $81.8 \%$ of the cases were classified correctly), where "less successful" is seen only by relative means - since the threshold of $75 \%$ was exceeded in all three groups, meaning that the analysis holds good explanatory power. 
The misclassifications can be due to the fact that from the original five groups of IEF, three groups were created. This was necessary for the analysis to proceed, but the critical assumption can also be related to the $\mathrm{GCl}$ classification of countries. In the original setup, there are also two transition phases in addition to the three stages of economic growth due to Porter, which are "merged" in order to have a categorization based on three groups. Therefore, the overall classification was not endangered.

It is important to notice that all innovation-driven economies except USA were categorized correctly for the corresponding degree of their economic freedom. The analysis based on three groups was resulted with two discriminant functions. The first discriminant function showed a higher correlation with variables which can be considered as the institutional framework which can support new and growing firms. Intellectual property rights, quick access to utilities (gas, water, electricity, sewage), support of science parks, business incubators and government, reduced bureaucracy by offering a wide range of government services through a single agency and the environment of increased opportunities are key topics which can be associated with the first discriminant function. All variables except the last one were positively correlated with the first discriminant function.

The second discriminant function showed a higher correlation with variables which can be considered as the perceptual components for becoming an entrepreneur. Perceptions as a fuzzy front-end to generation of new knowledge was the point of view of Erkut (2016b). Entrepreneurship as a career choice, training programs, opportunities to create new firms, financial possibilities and equal opportunities based on gender equality are the key topics which can be associated with the second discriminant function, at first forming the perception of what entrepreneurship means by describing it in terms of the perception of the availability of opportunities. Whereas the opportunities were negatively correlated with the second discriminant function, financial possibilities and training programs as well as entrepreneurship as a career choice were positively correlated.

In the original five categories categorization of IEF in 2010, Chile was categorized as a "mostly free" country. Due to lack of observations for "free" countries, the two categories were merged to have the category of "mostly free/free" countries. Chile was misclassified as a "moderately free" country. Since Chile's overall freedom score, 77.2, is very close to the lower boundary of 80 points for being a free country, it is interesting to see why Chile was misclassified. From the detailed evaluation of the ten economic freedoms, it can be seen that Chile has an especially high score for property rights (Miller \& Holmes, 2010, p. 148).

According to the GEM NES global-national level data, the average value for Chile corresponding to the effective enforcement of intellectual property rights is 3.0 - which means "neither true nor false" in the Likert scale. Also the statement on the effective support of science parks and business incubators was rejected by the experts from Chile in average (2.72). Therefore, not only the property rights were differently assessed (since IEF focuses on the property rights in a more general sense), but also business freedom was seen as more restrictive than it appears to be. Without some sort of support for start-ups, it is harder to enter into markets. Indeed, one can also say that based on the subjective opinion of experts, a more pessimistic evaluation of the country's economic freedom is realized as a result of the analysis. Corruption and high income taxes are the 
weaknesses listed by the IEF for Chile (Miller \& Holmes, 2010, p. 147); they have to be taken into account for explaining the pessimistic evaluation.

Also for Ecuador, the classification was not precise. In the original categorization, Ecuador was categorized as a "repressed" country; in the analysis, it was belonging to the group of "repressed/mostly unfree" countries, whereas it was classified by the analysis as a moderately free country. Interestingly, the result driven from the experts' survey gives a more optimistic view of the degree of economic freedom.

An important point for Ecuador is the increasing government spending after the 2007 constituent assembly referendum (Miller \& Holmes, 2010, p. 180). Since government spending is generally associated with short-term positive economic effects, this may also influence the opinion of the experts. From the global-national level GEM NES dataset, it can be seen that the statement "In my country, new or growing firms can get good access to utilities (gas, water, electricity, sewage) in about a month" has for Ecuador the national average 3.85 - which is closer to 4, "somewhat true" in Likert scales. According to the 2010 report of IEF, the regulatory environment has a negative effect on the start-ups (Miller \& Holmes, 2010, p. 180). In this case, the opinion of the experts is different.

In the 2010 IEF, Uganda's categorization corresponds to the category of a "moderately free" country. The result of the analysis suggests that Uganda is a "repressed / mostly unfree" country. Also in this case, experts' opinion on the issue of intellectual property rights can play a role. The national average for Ugandan experts on the effective legislation of intellectual property rights corresponds to 1.48 - in Likert scales, 1 is "completely disagree" and 2 is "somewhat disagree". Interesting for the Ugandan case is the different evaluation of IEF and GEM NES global-national level average value for the role of government programs supporting new and growing firms.

The Ugandan national level average value corresponding to the effectiveness is 2.03 - the experts disagree on the effectiveness of government programs in average, whereas the 2010 report of IEF says that "reforms have enhanced the entrepreneurial environment and fostered growth" (Miller \& Holmes, 2010, p. 423). Uganda is below the world average for the time needed to start a business ( 25 days for Uganda, 35 days as world average) (Miller \& Holmes, 2010, p. 424); therefore, there must be other factors that cause this divergence of interpretation, which is again subject to a more specific evaluation and analysis.

The last misclassified case is USA. The overall economic freedom score of the USA was 78.0 for 2010 - two points behind the threshold for being an economically free country, categorized as "mostly free". As the categories merged, USA was in the group of "mostly free/free" countries. According to the results, USA was misclassified as a "moderately free" country. Both datasets are from the period of global economic and financial crises. Since USA was at the centre of these crises, it can be said that the experts' evaluation was more pessimistic than the evaluation of IEF - the "crisis" effect. This can also be understood from the sharp drop of seven economic freedoms out of ten for the US (Miller \& Holmes, 2010, p. 432), whereas in the previous evaluations USA was categorized as a free country. 


\section{CONCLUSIONS}

Based on the empirical findings of the study, it can be said that subjective (GEM NES) and objective (IEF) data reflect the same tendencies concerning entrepreneurship and economic freedom. Intellectual property rights, quick access to utilities, a well-functioning bureaucracy and a government supporting entrepreneurs are important factors to understand the interactions between these central concepts. The findings are in line with Ockey's (2011) contribution showing the close relation between economic freedom and intellectual property rights as well as with McMullen et al. (2008) work explaining entrepreneurship with economic freedom. Furthermore, the findings can also be associated with the findings of Kuckertz et al. (2016) showing the variation of influence factors according to the stage of economic freedom.

The contribution of this paper to the literature is based on four points: First, it was shown that a balanced collection of objective and subjective data is necessary for entrepreneurship research, which was also the point of view of Coduras and Autio (2013). Second, a combination of both perceptions and infrastructure support in a wide sense were identified as explanatory clusters of variables for the classification of countries according to their stage of economic freedom. Third, in particular, it was empirically tested that with GEM NES data, IEF can be forecasted to a large extend, although some misclassified cases were observed; both are important for the construction of GEDI.

The fourth contribution of this paper is based on the perspective of an entrepreneurially driven market process (Kirzner, 1997). The role of perceiving opportunities as well as the role model of entrepreneurship and support opportunities build an important cluster of variables in the analysis. This cluster is a reflection of the role of perceiving conditions during the generation of new knowledge and the introduction of novelties to the economy.

Still, some research limitations need to be highlighted. The research was done with data from 53 countries which are covered in both sources; however, due to methodological difficulties, the original five-category IEF was reduced to a three-category IEF in order to have enough observations in every group. Also the original $\mathrm{GCl}$ classification was reduced to three categories instead of having two additional transition phases. These were necessary steps for proceeding with the analysis, but they resulted in some misclassifications. Furthermore, Likert scaled variables from GEM NES were treated as interval scaled in line with Brown (2011) and Coduras and Autio (2013) although some researchers classify Likert scaled variables as ordinal scaled. This is known to the author of the paper; the methodological issues were kept in line with the research program defined by Coduras and Autio (2013).

Overall, it is necessary to collect both objective and subjective data with respect to entrepreneurship, since only the combination of hard facts and subjective perceptions can give an overview of how free a country is in terms of its inhabitants' entrepreneurial activity, which is the driving force behind markets (Kirzner, 1997). 


\section{REFERENCES}

Ahlstrom, D., \& Burton, G. (2010). International management: Strategy and culture in the emerging world. Mason, $\mathrm{OH}$ : South-Western Cengage Learning.

Audretsch, D.B., \& Thurik, A.R. (2000). Capitalism and democracy in the 21st Century: from the managed to the entrepreneurial economy. Journal of Evolutionary Economics, 10, 17-34.

Bosma, N., Coduras, A., Litovsky, Y., \& Seaman, J. (2012). GEM Manual: A report on the design, data and quality control of the Global Entrepreneurship Monitor. London: Global Entrepreneurship Research Association (GERA).

Brown, J.D. (2011). Likert items and scales of measurement? Shiken: JALT Testing \& Evaluation SIG Newsletter, 15 (1), 10-14.

Coduras, A., \& Autio, E. (2013). Comparing subjective and objective indicators to describe the national entrepreneurial context: The Global Entrepreneurship Monitor and the Global Competitiveness Index contributions. Investigaciones Regionales, 26, 47-74.

Diaz-Casero, J.C., Diaz-Aunion, D.A.M., Sanchez-Escobedo, M.C., Coduras, A., \& HernandezMogollon, R. (2012). Economic Freedom and Entrepreneurial Activity. Management Decision, 50 (9), 1686-1711.

Erkut, B. (2016a). Structural similarities of economies in competition and innovation - a decision tree based approach. Studia Oeconomica Posnaniensia, forthcoming.

Erkut, B. (2016b). From perceptions to new product development: product innovation \& market shaping. 2016 NeuroPsychoEconomics Conference Proceedings, 34.

Gustafson, J.W. (1992). Entrepreneurship, Ideology and Economic Theory: An Appraisal. The Journal of Economics, 18, 1-7.

Hanke, S.H., \& Walters, S.J.K. (1997). Economic freedom, prosperity and equality: A survey. Cato Journal, 17(2), 117-146.

Hayek, F.A. (1945). The use of knowledge in the society. The American Economic Review, 35(4), 519-530.

Hayek, F.A. (1989). The pretence of knowledge. The American Economic Review, 79(6), 3-7.

Heckelman, J.C., \& Stroup, M.D. (2000). Which economic freedoms contribute to growth? Kyklos, 53(4), 527-544.

Heritage Foundation (2016). 2016 Index of Economic Freedom. Retrieved on June 30, 2016 from http://www.heritage.org/index/about

Holmes, K.R., Feulner, E.J., \& O'Grady, M.O. (2008). 2008 Index of Economic Freedom. Washington, DC: The Heritage Foundation.

Kelley, D.J., Bosma, N., \& Amoros, J.E. (2011). Global Entrepreneurship Monitor 2010 Global Report. London: Global Entrepreneurship Research Association (GERA).

Kirzner, I. (1997). Entrepreneurial Discovery and the Competitive Market Process: An Austrian Approach. Journal of Economic Literature, 35(1), 60-85.

Kuckertz, A., Berger, E.S.C., \& Mpeqa, E. (2016). The more the merrier? Economic freedom and entrepreneurial activity. Journal of Business Research, 69, 1288-1293.

Lehmann-Waffenschmidt, M. (2008). Strukturähnlichkeiten und -ungleichheiten evolvierender Ökonomien. Wissenschaftliche Zeitschrift der Technischen Universität Dresden, 57, 105-109.

McMullen, J.S., Bagby, D.R., \& Palich, L.E. (2008). Economic freedom and the motivation to engage in entrepreneurial action. Entrepreneurship Theory and Practice, 32(5), 875-895. 
Miller, T., \& Holmes, K. (2010). 2010 Index of economic freedom. Washington, DC: The Heritage Foundation.

Miller, T., \& Kim, A.B. (2010). Defining economic freedom. In T. Miller \& K. Holmes (Eds.), 2010 Index of economic freedom (pp. 58-62). Washington, DC: The Heritage Foundation.

Ockey, J.R. (2011). Economic freedom and fiscal performance: A regression analysis of indices of economic freedom on per capita GDP. Undergraduate economic review, 8(1), Article 9.

Porter, M.E. (1990a). The competitive advantage of nations. New York: Free Press.

Porter, M.E. (1990b). The competitive advantage of nations. Harvard Business Review, 68(2), 7393.

Snodgrass, D. (2008). Alternative business enabling environment rankings - a review. Washington: United States Agency for International Development.

Wong, P.K., Ho, Y.P., \& Autio, E. (2005). Entrepreneurship, innovation and economic growth: Evidence from GEM data. Small business economics, 24, 335-350.

\section{Author}

\section{Burak Erkut}

Burak Erkut is lecturer and PhD candidate at the Professorship of Managerial Economics, Faculty of Business and Economics, Dresden University of Technology (Germany) where he focuses on innovation and shaping market processes from the perspective of evolutionary economics. He holds a BS in Economics and Management Science and an MS in Economics from the University of Leipzig (Germany). In the past, he worked at the University of Leipzig as a teaching and research assistant in microeconomics, macroeconomics and statistics and made his own research project at Halle Institute of Economic Research (Germany) on the economic aspects of a Cyprus solution.

Correspondence to: Burak Erkut, BS, MS; Dresden University of Technology; Faculty of Business and Economics; Professorship of Managerial Economics; Helmholtz Street 6-8, 01069 Dresden, Germany; e-mail: Burak.Erkut@tu-dresden.de

\section{Acknowledgements and Financial Disclosure}

I would like to thank Prof. Roland Schuhr for being my supervisor for my master thesis at the University of Leipzig, which eventually led to this article. Furthermore, I would like to thank Agnieszka Zur from Cracow University of Economics, four anonymous referees and participants of the 8th International Scientific Conference Entrepreneurship and Beyond (ENTRE 2016) in Krakow (Poland) for their valuable comments.

\section{Copyright and License}

This article is published under the terms of the Creative Commons Attribution - NonCommercial - NoDerivs (CC BY-NC-ND 3.0) License

http://creativecommons.org/licenses/by-nc-nd/3.0/ 